\title{
Best of Both Worlds: The Lived Experiences of Students Who Belong to an Interracial Family
}

\author{
Julius A. Reyes, Ed.D. , Ibrahim J. Sailani Nezafat , Fatima Khadija L. Anami , Ilonah Angelica \\ B. Balatbat, Bria Angela A. Jove
}

\begin{abstract}
The Philippine School Doha registrar's data shows that the number of interracial students has been exponentially increasing for the last three years concerning its relocation to a more massive campus. This paper aims to learn and understand the different perceptions and experiences encountered by interracial students.Method: This study used a qualitative approach that utilized phenomenology as the research design to understand the lived experiences of students who belong to an interracial family, relative to the central question: "How do students with an interracial family adapt to their culture?" Furthermore, this study focused on the specific question: "What are the common social adjustments experienced by the students who belong to an interracial family?" Findings: Findings have shown the different social adjustments of students who belong to interracial families in terms of their ethnicity, language proficiency, enculturation, and lifestyle. Conclusion: Interracial students experienced difficulties as they have to adapt to a multicultural environment and manage academic \& family challenges simultaneously. Recommendation:The researchers recommend a further investment of time and observation in this research in order to cover every aspect relating to interracial students for more significant variance and to avoid biases as this could not often be accepted by readers of all races, and conflicts could happen.

Index Terms - interracial, adaptation, multicultural, enculturation.
\end{abstract}

\section{INTRODUCTION}

The Philippine School Doha registrar's data shows that the number of interracial students has been exponentially increasing for the last three years concerning its relocation to a more massive campus. As the said educational institution becomes diverse, it experiences struggles due to the students' cultural differences.To clarify some of the general terms in this paper, it is defined that a multiracial person is someone with biological parents from two or more of the designated categories (Humes, et al., 2011, as cited in Harris, 2013). Multiracial individuals are those who have parents with origins from two or more racial or ethnic groups. This approach arguably allows for an inclusive and broad definition of individuals with mixed heritage backgrounds (Phinney, 2006, as cited in Chan, 2018). The interracial group is comprised of a heterogeneous group of individuals with a combination of racial and ethnic identities. Though inherently

Julius A. Reyes Ed.D.1,2,3, Ibrahim J. Sailani Nezafat ${ }_{1,2,3}$, ,Fatima Khadija L. Anami ${ }_{1,2,3}$, , Ilonah Angelica B. Balatbat ${ }_{1,2,3}$, , Bria Angela A. Jove $1,2,3$

1. Philippine School Doha, Doha, Qatar

2. Research Development, Accreditation and Publication Office, PSD, Doha, Qatar

3. Research Capstone Project, PSD, Doha, Qatar diverse, early researchers categorized multiracial individuals into specific minority groups based on the one-drop rule of racial classification (hypodescent; Fernandez 1996; Root 1992, as cited in Fisher, et. Al., 2014).

Ethnicity, on the other hand, captures shared cultural heritages based on language, customs, and history (e.g., Chinese, Korean, Vietnamese, and Japanese) (Chan, 2018). Given the considerable overlap and similar social creation of these constructs, the current study is also consistent with the views of contemporary researchers, who have tended to prefer the term, ethnic-racial identity (ERI). More specifically, ERI captures "experiences that reflect both individuals' ethnic background and their racialized experiences as a member of a particular group, which can include race experiences such as discrimination" (p. 23; Umaña-Taylor et al., 2014, as cited in Chan, 2018).

Being in a foreign environment can cause difficulties in learning how to address unfamiliar situations adequately. Based on the data that the researchers conducted, some interracial students face challenges in coping with the Philippine Educational Curriculum. Moreover, they are not used with the practices in the institution because different from their own. Some of the negative aspects include accusations of racial inauthenticity, forced-choices, and others-imposed racial categories for multiracial individuals (Franco, Katz, \& O'Brien, 2016). Several of these challenges are related to cultural issues such as acculturation, racial/ethnic identity, gender, sexuality, immigration status, and perceived racial/ethnic discrimination (Arellano-Morales \& Sosa, 2018; Gamst, Liang, \& Der-Karabetian, 2011). It may also include pressure to fulfill their parents' desires, conflicting cultural values, racial inequality, and limited social support for pursuing nontraditional career paths (Ma, Desai, George, San Filippo, \&Varon, 2014). On the contrary, there are also some positive aspects of having a multiracial identity, which includes: positive feelings about an individual's racial identity, higher levels of psychological well-being, flexible cognitive and behavioral strategies. These are also used to navigate different contexts, flexible identity, a sense of multiracial pride, and an appreciation of differences (Gaither, 2015; Saladhuddin\& O'Brien, 2011). According to Thornton (1996), as cited by Sanchez-Paramo (2014), children of mixed racial and ethnic heritage have unique advantages. Individuals who are socialized as multiracial frequently 3 have an enhanced sense of self and identity, and higher intergroup tolerance, language facility, appreciation of minority group cultures, and ties to single-heritage groups than do monoracial people (Sanchez-Paramo, 2014).

This study also took a different perspective on this matter, this time with the consideration of the students' 
multiracial family. It is where the researchers find their basis of the multiracial student's demographics, as this is where they begin to learn about their cultures first-hand before exhibiting to the social world. Among multiracial individuals from a variety of racial backgrounds, having a more integrated identity is associated with more diverse cultural exposures (Viki\& Williams, 2014). In this case, interracial families and the parents of mixed-race children, in particular, have always shown a strategic course through the racial structure of a society, wherever it may be around the world. It is believed that cultural contexts provide a culturally diverse set of values and expectations about what is considered developmentally and socially desirable and acceptable (Sung, 1985, as cited in Han, 1996). These kinds of situations between multiracial parents have been interpreted by one of the participants of this research. Moreover, cultural conflicts occur when three of the following conditions are met (Sue and Chin, 1983, Sung, 1985, as cited in Han, 1996): (a) members of one particular culture come into contact with the norms, values, and behavioral patterns of another culture, (b) the two cultures conflict or differ from each other, and (c) conformance to each culture is rewarded and socialized (p.380).This paper aims to learn and understand the different perceptions and experiences encountered by interracial students. It includes the way of adjusting and coping with the immediate environment that they are not accustomed to. The researchers interviewed with selected students from Philippine School Doha who fit into the category that is studied in this paper. Many factors can contribute to the identity and different experiences of an individual (Choi-Misailidis, 2010). Nevertheless, through the interview, the researchers' narrowed it down into four major themes, which are: enculturation, language and proficiency, ethnicity, and lifestyle. Each theme corresponds to their outlooks and aims to further explain their lived experiences as an interracial Student in a Philippine Curriculum-based school.

This study is essential in developing methods for alleviating and stabilizing the interracial students in Philippine School Doha. Making them feel left out is the last feeling that they should opt to. A multiracial individual's identity flexibility appears to set a foundation in fostering his or her cognitive flexibility, either through having a fluid identity, having to navigate and negotiate a variety of social contexts, or being able to identify and associate with multiple racial/cultural groups (Bonam\& Shih, 2009; Gaither, 2015; Gaither, Sommers, \&Ambady, 2013; Miville, Constantine, Baysden, \& So-Lloyd, 2005).

A numerous amount of people would benefit from this study. First, would be the teachers. They would be able to benefit from the way that they teach so that they can learn ways on how to improve and make interracial students learn better. Because of this, there is a high chance that interracial students would understand and comprehend the lessons better since they are both on the same page. Second, are the parents of the respondents. They tend to handle the challenges of race differently. They will benefit from this paper due to the reason that they will learn the different difficulties and hardships that their child is experiencing.

\section{METHOD}

\section{Research Design}

This study used a qualitative approach that utilized phenomenology as the research design to collect the results. The central concern of this approach is to understand the importance of the experiences, feelings, and perceptions that participants share within a common ground (Padilla-Diaz, 2015). Phenomenology is concerned with the study of the experience from the perspective of the participants. Therefore, the methodology does not include a hypothesis or any preconceived ideas about the data collected (Center for Innovation in Research and Training). The researchers collected data through in-depth interviews of their respondents.

It shared the theoretical conclusions when researchers are in such of the results of particular natural phenomenon (Speedy Paper). A phenomenological design was applied in this study as it is intended to recognize the experiences, feelings, and perceptions of the students who belong to an interracial family.

\section{Research Locus and Sample}

This study is conducted at a learning institute founded in Qatar, Philippine School Doha (PSD). PSD has already achieved many accomplishments, and it also has been serving the Filipino community ever since it opened in October 1992. This school selected because of the presence of the accessibility of guidance from their research teacher.The participants for this study were among the students who belong to an interracial family, specifically, students who study in Philippine School Doha. The participants selected through the qualitative purposive sampling strategy. The participants met the criteria created by the researchers. It is according to their nationality and years enrolled in Philippine School Doha.

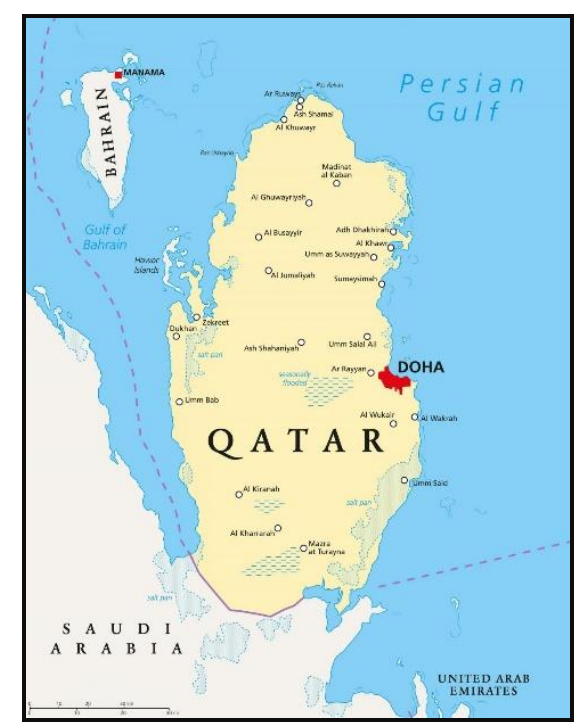

Figure 1 Map of Qatar taken from Maps QATAR 


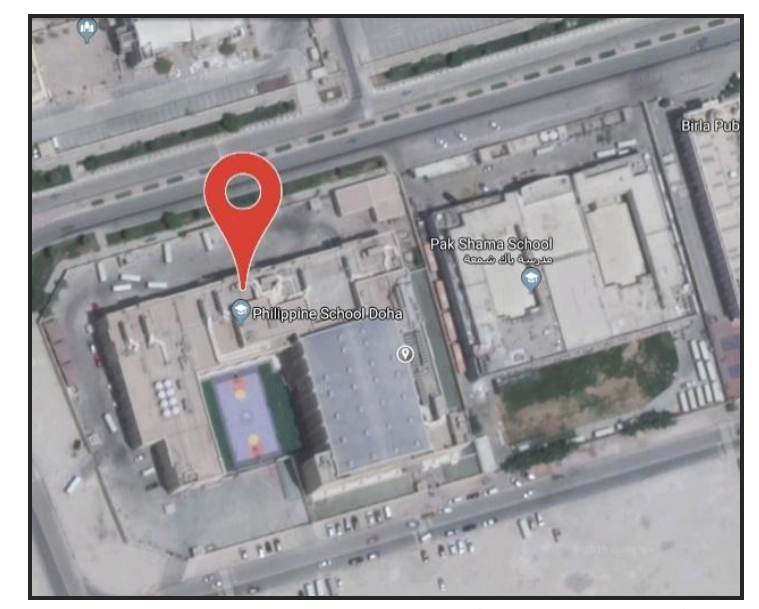

Figure 2 Location of Philippine School Doha, State of Qatar, taken from Google Maps

\section{Data Collection and Ethical Consideration}

Due to the purpose that the students' experiences are not easily understood by means of quantification, this study carried out through the phenomenological method of research. From the pool of PSD Senior High School students, five participated in a semi-structured interview. Criteria for the selection included all of the following: (a) a bonafide student of Philippine School Doha; (b) must come from an interracial family and background; (c) availability and willingness of the participant to be interviewed. The subjects the study were of mostly from the Senior High School Department. The data needed to be was then acquired through a semi-structured interview that used instruments such as the robotfoto and 25 validated interview guides. The robotfoto sought the biographical sketch of the participants, namely their names, age, gender, grade level, language/s spoken, and years enrolled in Philippine School Doha. The said interview guide used in acquiring the participants' perceptions about certain issues about the chosen topic and to explore specific experiences that will later be analyzed and described. The interview proper is documented through audio recordings.

The data gathered from the audio recordings were transcribed in verbatim and assured the participants that their responses would be confidential, and possible indicators of identity will be censored or hidden.Before the interview proper, thorough preparations are done, which includes the specific instruments needed. The researchers also sought approval from the participants through a written consent form in which each participant signed.

\section{Data Analysis}

The researchers followed a step by step process to analyze the collected data: (1) listening through the responses of each interviewee to understand their perceptions; (2) transcribing the data that were said directly by the participants which are known as the emic transcription; (3) transforming these emic transcriptions into etic transcriptions from the researcher's understanding of the direct responses of the participants; (4) classifying formulated categories into a group of themes viadendogram; (5) creating a simulacrum as a visual representation for the results or findings; (6) putting these themes into triangulation and member checking procedure to ensure the credibility and trustworthiness of the data.

\section{FINDINGS}

This phenomenological study explains the lived experiences of students who belong to an interracial family, relative to the central question: "How do students with an interracial family adapt to their culture?" Furthermore, this study focused on the specific question: "What are the common social adjustments experienced by the students who belong to an interracial family?"Within interracial and multicultural families, individuals may have unique experiences of ethnic identity formation due to their parents' different ethnic and cultural backgrounds (Hsieh, 2016), Adolescents and young adults developed their ethnic identities, behaviors, and other significant culture through the process of socialization. (Gonzales-Backen, 2013; Salgado de Snyder, Lopez, \& Padilla, 2006).

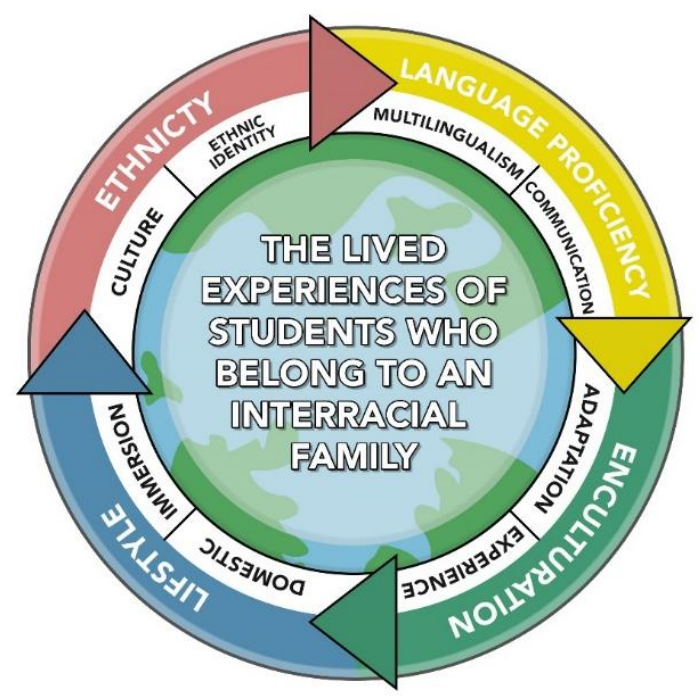

Figure 3 Simulacrum on Lifestyle, ethnicity, language proficiency and enculturation

Figure 3 shows the simulacrum focused on four major themes: ethnicity, enculturation, language proficiency, and lifestyle. These themes form a union through the shared social adjustments experienced by the students from interracial families. Furthermore, these themes show the different aspects of adjustments that the students go through by the study conducted.

\section{Ethnicity}

The parents' ethnic backgrounds from interracial families are closely linked to the child's ethnic identity. Culture plays a great part in a person's ethnic identity. It influences his/her views, values, beliefs, and perception of the world.

As an interracial child, it is essential to know his/her ethnic identity as it will let him/her perceive and respond better to ethnic information in his/her environment. The respondents were knowledgeable of their parents' culture and origin. A respondent implemented and adapted to both cultures, depending on where he/she is. However, another 
respondent practiced the more dominant one. As averred by the respondents:

"I am clear about my parent's culture and implemented to myself both cultures depending on where I am. Moroccan culture is more of Arab because it originated from the Arabian Peninsula. Both cultures are varied and there are barely any similarities. (P5)"

"I'm aware of the Filipino culture since I lived in the Philippines with my mom, and it is more dominant than the Arabian culture. (P4)"

Also, interracial marriage is a type of union between two individuals coming from different ethnic groups or backgrounds. An interracial family consists of members from diverse origins and cultures. It is exposed to cultures that are different from their own. A family has a significant role in shaping the child's development, such as the values and our way of relating to others. It has a significant influence in terms of racial and ethnic socialization.

As an interracial child socializes, he/she is influenced by the different cultural values and norms that serve as the guidelines for our everyday life. Interracial families bring diverse perspectives and understandings of culture. A respondent affirmed:

"Being in an interracial family is difficult because of the difference in culture, for example, when relatives visit our house, my Iraqi family is strict while my Filipino family is more carefree and has fewer restrictions. (P4)"

One of the factors that influence culture is family practices and traditions. It influences how one evaluates and interprets everything around him/her. As one respondent shared his/her experience regarding how to cope with this:

"There are different celebrations that I celebrate, and that is how I maintain and cope up with the different cultural traditions. (P2)"

Growing up with two different cultures, it is important for a child to feel secure and to know their culture. Sometimes it can create conflict and confusion for one who feels stuck between.

With the difference in the practices of the respondent's parents, there are struggles wherein the respondent does not know where to identify himself/herself. Parents have different ideas about discipline and other practices. These differences can affect how a child views the parenting style.

"Yes, I have been in a situation where my parents both argued as to where I would study for college. My mother told me not to go to the Philippines because I am not used to the way they live, and I might be caught in trouble. My father says otherwise. So basically, they are trying to pressure me as to what culture I should prioritize. (P5)"

"Yes, I've been in one situation where I was forced to choose between Catholic or Buddhism, and I just chose to mix both of the religions but focus on being a Catholic more. (P2)"

Furthermore, all of the mentioned experiences have a significant impact on one's life. They can lead to a positive effect; they can make people more aware of the different cultures and be open up with new experiences and opportunities. However, it can also result in problems and challenges. These include language barriers, prejudices and discrimination, and others.
It takes time for a person to adapt or learn a new culture. If a person immersed in a culture that is unlike his/her own, he/she may experience culture shock and difficulty in apprehension. A person who lived or stayed in a foreign country for some time has experienced the differences in customs, beliefs, and behaviors. The person confirmed:

"I mostly practice the culture of my father because it is easier compared to the Filipino culture, and also I am more familiar with the American culture when compared to the Filipino culture. (P1)"

"I tend to lean more towards the culture I am more comfortable with because I feel embarrassed when I practice a culture I am not familiar with. (P1)"

"I practice Filipino culture because I use it at home and in school. (P4)"

It can be effortless for some people to stick with what culture they are used to rather interacting with people who are different from them. Some of the respondents can easily relate to other cultures because there is no difference in the culture they practice.

"It is easy to relate to them, even if our culture is not the same. We can still talk to each other, and It's actually easy to diverse if you actually adapt to them. (P2)"

"I do not feel any differences being friends with people that have differences in culture because the people In school knows that I have problems in communicating in Tagalog, so they adjust their way of socializing. (P1)'

"I have been here for ten years already, and when I came to a Philippine School, I somewhat lost my old tradition and adapted to the social world of the school. (P2)"

Discrimination is a continuing issue that people experience daily. A person's race is not only the controlling factor of being discriminated, but it can also be his/her sexual orientation, religious beliefs, cultural background, and many more. The respondents reflected on their own experiences and awareness of discrimination and how this affects or influences their identity. They responded to these experiences in various ways. There were several experiences stated by some of the respondents on associating with people having different cultures:

"I have been discriminated since I was young; I've been labeled a terrorist just because I'm Arab. They sometimes hate you or dislike you for being half, I usually ignore it because I can't do anything about it, but I don't have to please them and have them accept me for what I am. (P4)"

"My experience wasn't in school because I tend to stand up for myself, but it did happen online. It was because I'm Arab, and the majority of Arabs are Muslims, so I would see racial slurs like terrorists or Osama Bin Laden's daughter. It hurts, so it makes me question, how do you just generalize people but then it drives me to read more about both of my culture and beliefs."

These affirmations indicate various experiences of the respondents on associations with other people. Unfortunately, when two cultures meet, this can sometimes lead to prejudice or discrimination due to the different beliefs and practices. This can affect a person's well-being. Nonetheless, when two or more cultures come together, people learn from one another and help understand the different perspectives they encounter. Feeling connected and associated to a certain group is essential for a person's mental 
health and well-being as it helps him/her to feel appreciated and welcomed. As experienced by some of the respondents:

"I do not get left out since I can socialize with Filipinos because I grew up in the Philippines. (P4)"

"Yes, to be honest, there are times that I was left out from my group; this is either the interest in a topic or other factors like ethnicity. (P5)"

Culture influences people the way they perceive the world. People with different cultures have gone through different experiences of socialization. Generally, a person's ethnicity makes his/her social qualities, traditions, beliefs, language, and religion.

\section{Language Proficiency}

Language plays a significant role in adjustment to a different environment. It is hard for an interracial student to adapt to the community they live in. It is very common for students who come from interracial families to have difficulties in language proficiency. Language proficiency is important because language is a system by which humans can use to communicate. Interracial children can learn and use the languages spoken both of their parents with proficiency; these give them the capability to adapt, but some interracial children are more proficient in one language more than the other. Having this situation, interracial children encounter various difficulties in adjusting to their social life. Particularly, interracial children studying in a Philippine school and communicating with classmates, friends, peers, or other people in the institution who are speaking languages that are different from them.

The majority of the respondents experienced a similar situation. The majority of the participants' social life was affected by the difficulty in communication with lack of proficiency with the language commonly spoken in school. A stated by some respondents:

"Since I have a different culture and I know many languages which is conflicting because when they are conversing in deep Filipino, I tend not to understand since I only know a range of simple Tagalog words and them conversing in deep Filipino makes me feel left out since I can't communicate that much. (P2)"

Some participants have problems in interacting with their peers because of the barrier in language.

"It affects me by giving me a hard time socially interacting with my friends. (P1)"

"It affects me negatively because of language barriers. I don't really know much Filipino, so it would be difficult for me to converse in straight Filipino even though I understand the language, while it also affects me positively because I get to understand more people and not just limited to Filipino people. (P3)"

A participant can adjust to the environment because of having the ability to speak different languages, as stated:

"It depends on whoever is talking to you. It is good to be multilingual and have friends who can speak Arabic and Filipino. Just for everyone can understand, I would go for English because I am strong in that language. If ever I might encounter someone who can't speak English very well, I can also speak Filipino. (P5)"
Language plays a vital role in communicating and studying. Lack of proficiency in the language used in school affects one's learning.

"It affects me when I try to understand the words the teacher says because there are times in other subjects where the teacher gives activities and explains them in Tagalog. (P1)"

"It affects me in terms of the subject of languages like the Filipino subject or any subjects that have that language that I barely know and speak because there would be some words that I do not understand in the Filipino language, that's when it drags my grades down, so I need assistance from my teachers and parents. (P3)"

Most participants have a disadvantage in their academics since they are not fluent in the language taught in the school.

"Yes, since I know a lot of languages, it's hard for me to choose between different schemata of languages in my mind. It's also hard to converse with the teacher and the other students since I have different ways of talking in the house, in school, and to other people. (P2)"

Some of the respondents were not affected by these factors: As stated by the respondents:

"Being an Interracial child, I don't think my different cultures affect my grades. (P2)"

"It does not affect me that much because I do not seem to see the academics in being interracial. It is the same thing you have to study, and you also have a future to consider. (P5)"

"As an interracial child studying in a Philippine school, it doesn't really affect me because I can communicate with other students since I can speak the same language as them. (P4)"

A participant was not affected due to the ability to speak Tagalog since he/she exposed to different cultures for long.

"It does not affect me because I can speak Tagalog, and I study in a Philippine school. At first, they were shocked, but now they see me as a Filipino. (P4)"

There are also advantages to being an interracial child. If one could learn from the two cultures effectively, a person will learn more than one language and will able to adapt to both cultures. As some respondents said:

"It has a positive effect if you really understand the language, and you could easily communicate with anyone that speaks the same language. It opens a new side of you, and you can branch out to people and not just in one group. (P3)"

Fortunately, some respondents see the advantages of being in a multiracial family, as stated by some respondents:

"Having a multiracial family is not a disadvantage because you get to learn more cultures and have the ability to learn the lifestyle and to speak different languages. (P1)",

"It is advantageous because you will have the ability to be multilingual, which is the first thing. The second thing is that you can have more than one culture, which leads you to be more understanding and less biased when you go to both countries. (P5)"

Various factors affect how they adapt to the language difficulties they experience. These factors can give either negative or positive results. It also illustrates how the students were affected according to their language 
proficiencies and diverse backgrounds. Examples of these factors are the level of their base knowledge about the language, help from family members that are knowledgeable about the culture, and the group of people they interact with. As some of the respondents stated:

"I was barely able to cope up with the environment, especially the Filipino subject because I was self-taught until recently, they introduced the Filipino research subject, and it made it harder for me because I am not fluent in speaking and writing in Tagalog. (P1)"

"I ask for help from my close friends that are fluent in Filipino so that they can explain the words in a way that I can understand them. Yes, I find it very difficult at times, but there is always a way to overcome problems. (P1)",

"Coping up with the Filipino environment is easy since I'm used to it, and it's a blessing to be able to study here without any difficulty. (P4)"

Specifically, the people living around them can affect how well they cope and adapt. People like their family, friends, and peers they interact with. Despite having difficulties in some parts of communication, the students were able to find ways to interact and socialize with other people. Students can overcome this struggle by getting along more with the others at parties and hanging out with them more often.

"Yes, since I get lessons from my aunt about Philippine Culture and how I can go around it. (P2)",

"Sometimes, it's difficult, but I tend to try my best to speak Filipino even if it means googling and mispronouncing the words just to be able to communicate with them. (P3)"

"Having Filipino friends is fun since I get to learn more about the Filipino language and values with them. I cope up with them by adapting to their perspective. I do not find it hard. (P2)",

Even though coming from an interracial family has advantages, it also has disadvantages. One of them is a lack of proficiency in a language. Lack of proficiency in a language commonly used is common in children that came from an interracial family. It also poses difficulties in the social lives and learning of these children. These difficulties can be overcome with the help of other people and learning more about the language.

\section{Enculturation}

Enculturation is a process by which an individual learns the acts of culture and acquire those acts that are suitable or needed in a culture where they are currently exposed to. It is a collective experience that is mostly encountered by students who are part of an interracial family. These students have to adapt to the different cultures that are present in their family.

There was a student who was unable to adapt quickly to both cultures. Because there are two cultures in the respondent's family, the respondent learned a more dominant culture, which was more practiced than the other religion. A stated by the respondent:

"I do not, because I grew up learning about the culture in Qatar (P1)"

But not all of them experienced difficulties in the adaptation process. Some of them grew up with these households and therefore got used to their cultural surroundings. As stated by some of the selected participants:
"I don't need to adapt to the Filipino culture since I grew up there and I got used to the Arabic culture while living in Qatar for four years (P4)"

"Yes, because I am now 17 years old, and I've been to both countries, so adapting is not hard because it's all about getting used to it. (P5)",

These articulations display how adaptation is not viewed as a significant hindrance to some of the participants. They become standard in their lives. They deal with individual lifestyles present in their family. Through exposure, they were able to figure out ways on how to adapt to different cultures. Some of the respondents were able to change through immersion into different religions present in other families. They allowed themselves to interact and be part of both cultural practices. As a result, they adapt to both cultures. As stated by some of the respondents:

"I mostly practice the culture of my father because it is easier compared to the Filipino culture, and also I am more familiar with the American culture when compared to the Filipino culture. (P1)"

"I've been here for ten years already, and when I came to a Philippine School, I somewhat lost my old tradition and adapted to the social world of the school. (P2)"

"I don't really feel any different from them because I'm half-Filipino and Iraqi, and I can relate to them while having a different culture. (P4)",

These responses indicate how some of the students were able to adapt quickly through immersion. They encountered particular situations that established their personal growth and development. Additionally, they were able to accumulate knowledge and ideas about different cultures present in their families.

They were also able to find ways on how to adjust between the two cultures, as said by some of the participants: "I can adjust depending on where I am and the people around me, otherwise, there could be a misunderstanding, and you might end up with judgmental people. (P5)"

"I adjust to both cultures by either mixing them up or by dominating one culture over the other. For example, instead of celebrating Christmas, we just wait for the Chinese New Year. We alternate our ideologies. (P2)"

"I follow what is more appropriate and sometimes what is applied in terms of religion and cultures combined. (P3)"

Being an interracial person in a Filipino Community can result in difficulties when it comes to coping. It is proven by some of our respondents who experienced some of these difficulties, and their reason was that they found it hard to relate to the culture that they are not familiar with. Furthermore, they also compared their past experiences with the situation that they are in now. As averred by some of the selected participants:

"It feels like I'm at home, but at the start, it was tough for me to adjust because I was not used in spending time with Filipino people. The teachers in the school are more strict when compared to the teachers I had in the international school I transferred from. (P1)"

"It's hard to talk about it because there will be some people who you can see their Filipino values in them, but then you can also see people who don't apply it and go (P3)",

Although some of them experience these difficulties, it doesn't mean it's the same story for every 
respondent. Those left were the ones who were able to cope easily in a Filipino Community, as stated by these participants:

"I grew up in the Philippines, so I wanted a school with the same vibe, that's why I chose to study here in Philippine School Doha (P4)",

"My answer could be biased because I've only studied in a Philippine school. Studying in a Philippine environment is not bad; the school is open to all and is allowing foreigners to come to study. (P5)"

These responses are the same in terms of coping with the Filipino Environment. They had no difficulty in coping with their surroundings.

"Yes, as I said, nothing is really shocking, but I do not expect anything, so I guess that's why I easily cope. (P3)"

"Coping up with the Filipino environment is easy since I'm used to it, and it's a blessing to be able to study here without any difficulty. (P4)"

"I was easily able to cope up with the Filipino environment because they are really hospitable, open to any culture around the world, and friendly towards anybody. (P5)"

Alongside having the Filipino Community as their primary environment, them attending a Philippine School also contributes to their cultural formation. They experience difficulties in terms of the situation and curriculum of the school. One hindrance that causes them difficulty is the language barrier. To keep up with the environment that they are in, they find ways to deal with it as mentioned by the selected respondents:

"It does not affect me. It is hard to deal with, but it is not difficult to overcome the problems. (P1)"

"Since I've been here for 10 ten years, the language barrier has already been broken. But at first, it was hard to understand people, but since there is a Filipino subject, I try to learn more. (P2)"

"Sometimes, it is difficult, but I tend to try my best to speak Filipino even if it means googling and mispronouncing the words just to be able to communicate with them. (P3) "

"We sometimes use English and Filipino in the house to talk; because my dad studied in the Philippines, he can understand some Filipino words, so it wasn't hard to cope. (P4)"

Additionally, the subject of Filipino is a requirement. Although, since Filipino is not their only language, difficulties surfaced. These students tend to ask help in these type of situations as one participant stated:

"It is not difficult to understand, I've learned it alone because when I was a child, I'd speak in English, but I would try to understand what they're saying even though they can't really speak in English then there are some words that I remember, but sometimes deep words are difficult. (P3)"

"I do not really find the subject Filipino difficult to cope up with because I'm good at it, so I get a high grade. (P4)”

If ever they do encounter problems, they ask help to cope up with the subject. As some respondents mused:

"I ask for help from my close friends that are fluent in Filipino so that they can explain the words in a way that I can understand them. Yes, I find it very difficult at times, but there is always a way to overcome problems. (P1)",
"I have a basic vocabulary in Filipino, so if ever I encounter a deep word or a new word and I mostly ask my friends who understand fluent Filipino to help me out. (P5)",

Aside from dealing with possible language and academic barriers, communication with peers are also important. Hardships with interactions with pure Filipinos may be experienced due to probable differences in culture, language, and upbringing. However, based on the experiences from some of our participants, not a lot of difficulties were encountered with the interaction as expressed by the students:

"No, it is not very difficult for me because I am also a Filipino, I can understand them so that they can understand me too. (P5)"

"Most of my friends are Filipinos here and back in the Philippines so, I don't find it hard to communicate and adjust with them. (P4)"

Being friends with people who have a different culture from their own can affect one's capability to socialize. As alluded by the respondents:

"I do not feel any differences being friends with people that have differences in culture because the people In school knows that I have problems in communicating in Tagalog, so they adjust their way of socializing. (P1)",

"At first, it is kind of intimidating since you have not familiarized yourself with what they do, but you could ask them. However, this might be disrespectful, and they might go against it. You can learn the culture, and then you will end up adjusting to the community. (P5)"

Moreover, different respondents have different ways for how to deal with the environment in a Filipino based school. As mentioned by some of the participants:

"I try to adjust my personality and traits as well as taking in their culture like mostly following their culture instead of mine. (P2)"

"Like in every school I've been to in the Philippines, I relate to the Filipinos here. (P4)"

Generally, these manuscripts show how the respondents learn to adapt and adjust to the specific environment that they are in. They let themselves experience different ways on how to cope and deal with certain situations, which led them to develop flexibility, learn new knowledge, and gain new experiences.

\section{Lifestyle}

A way of living of individuals, which determines their interest, religion, health, behavioral orientations, and more. These aspects play a significant role in molding an individual's lifestyle. Lifestyle reflects the individuals' perception of themselves and believes they are realized by others, in short, an individuals' identity. Interracial children have a distinctive case as they acquire diverse cultures and traditions from their parents who have differing races. As stated by some of the selected respondents regarding the different cultural traditions present in their family:

"I am aware, my mother is stricter with the Filipino culture and with the kind of food she cooks, and the way she cooks is according to her culture. In the family, my dad and I are still not used to the food she prepares. There are differences in ways of living, but I could not explain it since I am not that familiar with the traditions. (P1)" 
"Yes, my father follows the catholic lifestyle like going to church or praying every noon, and my mother follows the Buddhist lifestyle like doing paypay and praying to different Buddhists. (P2)",

These articulations pinpoint that people's lifestyle varies concerning their culture and traditions. Interracial is a race involving and existing between different races or ethnic groups. As a child born with differing cultures, they have to adapt to the literature depending on which country they are. A selected respondent verifies this:

"Yes, because when I was little, I would be around my dad's family because they're here, but then I would also be small, and whenever I go to the Philippines, I'm with my Filipino family. (P3)",

"It depends on the situation between my parents. If go to Morocco, I would, of course, prioritize the use of Moroccan culture. Same thing for the Philippines too. (P5)"

However, in some cases, interracial students practice their other race due to pressure from their parents. As stated by a selected respondent:

"I am more on the Filipino side because my father wants me to be more Filipino than Moroccan. However, I apply the Arab culture with the Arab community and the same thing with being Filipino and their community. (P5)",

Corresponding to the statement above, some interracial students experience a conflict where they had to choose a side. The main reason for this is the students' plans for their future as well as their parents. Though parents are only concerned about their child's future, it is inevitable to feel pressured and confused in that situation, which then stimulates them to choose aside.

"Yes, it was when my parents made me pick which school I should enroll in the future and which country I should live in after I finish High school in Philippine School Doha. (P1)"

"Yes, I have been in a situation where my parents both argued as to where I would study for college. My mother told me not to go to the Philippines because I am not used to the way they live, and I might be caught in trouble. My father says otherwise. So basically, they are trying to pressure me as to what culture I should prioritize. (P5)",

As we discuss the school, some respondents face difficulties in their everyday life as a student in a Philippine educational institution wherein they are unaccustomed to the Filipino environment. This affects their ability to socialize with non-interracial students as they are interracial students. As stated by a selected respondent:

"It affects me by giving me a hard time socially interacting with my friends. (P1)"

As unique as interracial is for non-interracial individuals, it is a love-hate relationship for them. Another conflict that interracial students undergo is a comparison from their family towards non-interracial families. As stated by a selected respondent:

"I do because sometimes I feel a bit envious and think about how things would've been easier if I was just pure-blooded. I know the practices it is just that, I feel like sometimes I barely have any of their parts. I just feel like an outcast. (P3)"

Nevertheless, despite the complexity that students face as a child born with differing races. Interracial students believe that being an interracial benefit their ability to quickly comprehend people's perspectives and their ability to immerse themselves in people's culture and traditions.

"It is an advantage if you look mostly on the positive side if you are open and dare to learn the language that your family has then you would be able to understand other people's views and be able to open to them. It also gives you more groups of friends and communities that could give you support, and through them, you can learn so much. You would just internalize their food, songs, and the way they dress. (P3)"

\section{DISCUSSION}

Multicultural schools offer different opportunities for students to cultivate interpersonal cross-race ties. Racial diversity in a multicultural school setting alone is not enough to produce an environment that yields the benefits of the education that diversity potential offers. Students of different races must take the opportunity to socialize and build ties with each other (Arellano et al., 2009). As schools continue to grow in diversity, they are trying out various social adjustments. Interracial students must be aware of their surroundings as multicultural awareness is crucial to the growth and development of any organization and more so in schools where values are inculcated, and young minds are molded (Gulf News, 2018).

The individual differences of the students, such as gender, race, belief, and disabilities, can all determine the processes in which they will move through each stage of learning and racial socialization. Several aspects can also complicate the way that the students are able to advance through the processes. The experiences that make ethnic-racial minority adolescents and young adults, particularly aware of their ethnicity or race are often those that negatively highlight their ethnic-racial group membership, such as prejudice and discrimination (Gonzales, 2016).

\section{Ethnicity}

Ethnicity refers to groups that share a common identity-based ancestry, language, or culture. Each ethnic group has its interest, status, and right to protect and preserve their culture. (Mohamad, 2019) Ethnicity is one of the significant social identities we use in our daily lives (Worrell, 2015) and is a fundamental element of self-definition (Deaux, 2001). Ethnic identity is a measurement of the feeling of belongingness to a particular ethnic group (Epstein and Heizler, 2015). Personality develops as a person tries out different roles and attitudes in different environments, such as home, school, and others (Watson, 2019). Its development is considered vital as it can promote positive psychosocial and academic functioning (Rivas-Drake, et al., 2014)

Additionally, interracial marriage is used to describe weddings that take place between people of different ethnic, racial, or cultural backgrounds (Teasley, n.d.). Two or more different cultures are combined in this kind of relationship, providing the couple with unique experiences that shape their world view and also results in more customs practiced in their daily lives (Hsieh, 2016). The positive ethnic identity of the spouses and the positive attitude towards the partner's learning help their relationship to cope up with the difficulties 
or challenges (\& Lauer, 2017). The birth of a child in this kind of relationship brings numerous adjustments in parent's interpersonal relationships with their spouse, family, and friends, which is challenging. Interracial couples must learn to recognize and regulate new life emotions and experiences they are not yet familiar with in addition to deciding how they will relay each of their cultural values to their children (Rios, 2018).

An interracial child learns about their ethnicity through their interaction with others at a young age, mostly from their parents and home life. The environment they grow up in, the peers they interact with, and the type of relationship they have with their parents will influence whether the interracial child develops healthy or unhealthy ethnic or racial identities (Rios, 2018). Children from different ethnicities, cultures, and nationalities increasingly encounter and interact with one another due to several factors, including increasing mobility and migration (Hitti, Mulvey, and Killen, 2017).

The multicultural environments of adolescents and young adults should be considered, including family context, family socialization, discrimination, community, and general social climate concerning ethnic identity as it can impact the resulting ethnic identity formation (Gonales-Backen, 2013). Youth from different ethnicities, cultures, and nationalities increasingly engage with one another due to numerous factors, including increasing mobility and migration of those in search of a better quality of life, refuge from conflict, and economic stability (Bagci et al. 2014). Exposure to diversity is beneficial to youth, but only to the extent that students take up opportunities to make friendships across ethnic groups (Graham et al., 2014).

With the exposure to diversity, people categorize themselves and others into in-group and out-group members; these social categorization processes can have an impact on intergroup attitudes and behaviors (Hogg, 2016). Racial socialization is considered a process where a family transmits their values, traditions, and knowledge about race and culture from one generation to the next. (Raines, 2015). Parents from different cultural backgrounds may transmit more multiple perceptions, values, and attitudes to their children. This leads to multiracial and multicultural adolescents and young adults to have unique processes of ethnic identity formation (Hsieh, 2016).

Ethnic minority groups are more probable to encounter racism, prejudice, discrimination, and structural barriers, which can affect their positive wellbeing. (Raines, 2015). They face issues regarding their identity formation, fitting in with peers, school transitions; such tasks can seem more difficult and stressful for interracial youth (Goodyer\&Okitikpi, 2007). Experiences with discrimination are difficult to deal with at any age, but specifically for adolescents, they may be overwhelmed by the emotions caused by such harsh experiences (Han, 2012). Solis, P. (2017) said that (as cited in Solis et al., 2019), a person understands discrimination as "the set of practices that deny equal treatment or produce unequal results for certain social groups and result in the deprivation or undermining of access to rights and the reproduction of social inequality." It is useful to classify discrimination practices according to the type of consequences that they have. A primary classification, in this sense, could include three different types of practices (Solis, 2019):

a) Practices that deny or restrict access to the social sphere in question, for example: denying access to a school, a restaurant, or a job.

b) Practices that do not deny access but condition it or limit internal mobility once access has been achieved, for example: giving preference to some people over others for job promotions, medical treatment, or fair treatment within the justice system.

c) Practices regarding mistreatment that are not directly related to access or internal mobility. These practices significantly affect a person's life and can have relevant cumulative effects in the long term. For example, derogatory treatment at work, school, or any other sphere, involving nicknames, insults, contempt, and disregard.

There has been an advancing awareness of how culture influences people over the past few years. For instance, culture influences how one chooses to structure their world view and respond to life experiences (Rios, 2018).

\section{Language Proficiency}

Proficiency, as defined in the dictionary, is having the skill and experience for doing something. Language varies in everyday speaking and writing. The strength of cross-language transfer depends on the type of language proficiency task and the type of school outcome (Prevoo, et. Al., 2016).

Interracial children can learn the languages of both parents with proficiency; these give them the capability to adapt, but some interracial children are more proficient in one language more than the other. Having this situation leads to difficulties in their social life. Some students had problems in the students' way of speaking due to some reasons, such as fear of mistake, shyness, anxiety, and lack of confidence (Al-Nakhalah, 2016). According to a study conducted by San Miguel and Rogan (2015), to be effective in overall communication, these guidelines need embedding within a systematic approach that identifies to students who may be underperforming because of to a low level of English language proficiency. Statistical analyses revealed significant differences in language proficiency and multilingualism concerning academic performance. The highest mean GPA was evident among students who had reported high levels of self-perceived English language proficiency and among students who spoke at least three languages (Martirosyan, et. Al., 2015). Intercultural communication requires interlocutors to establish common grounds between language and cultural variations via meaning negotiation (God and Zhang, 2019). Academic attainment was assessed in reception and Year 2 (ages 6-7). Relative to monolingual peers with comparable English language proficiency, children with EAL displayed fewer social, emotional, and behavioral difficulties in reception, were equally likely to meet curriculum targets in response and were more likely to achieve goals in Year 2 (Whiteside, et. Al., 2017) how school problems are generally couched as one of the objectives, measurable deficiencies on the part of international students. This neglect leads, in turn, to a poor understanding of the English language capabilities of international students (Haugh, 2016). Another study conducted by Park, et. Al. 
(2017), revealing that they experienced accent-related problems, particularly in an educational setting. Findings show from a study conducted by Kim and Tatar (2017), showing the participants perceived the students' performances and the amount of interaction between domestic and international students negatively. These perceived roles were found to be associated with their multiple identities, as instructors and researchers, required and practiced in the context.

Since the usage of language is situation-specific, there are instances that the interracial person is rendered disadvantageous, depending on the communicators in the event. Based on the analysis conducted, the sounds that were commonly mispronounced by the students were vowels, consonants, silent letters, and the '-ed' form (Shak, et. Al., 2016). Ethnicity is a stronger predictor than English proficiency or acculturation, but English proficiency was still independently and additively predictive. This suggests that targeted support strategies for students with lower English language proficiency are still important, but that cultural differences should not be underestimated (Green, 2015).

There are instances, as mentioned previously, wherein the interracial student is rendered, disadvantageous. On the contrary, there are also instances wherein the interracial student can be rendered advantageous when things go their way, and there is an understanding between communicators, with the absence of language barriers and other forms of communication hindrances. The use of literature for language teaching can provide an avenue for advantages in language proficiency. Literature is a potentially valuable source for coming to good terms with an extensive range of enrichment in linguistic knowledge for successful language acquisition (Mart, 2017). Regression analyses demonstrated that nonverbal intelligence significantly predicted performances on verbal working memory and verbal and nonverbal inhibition tasks. It was concluded that nonverbal intelligence scores are better predictors of executive function performance than bilingualism or language proficiency (Rosselli, et. Al., 2016). Bilingual advantages in vocabulary learning depend on learning via the native language or dominant language because learning via the native language allows bilinguals to engage administrative skills that benefit learning (Bogulski, et. Al., 2019). These findings were done in a study conducted by Verreyt, et. Al. (2016) indicate that language-switching experience, rather than high second-language proficiency, is the critical determinant of the bilingual advantage in cognitive control processes related to interference resolution.

Interracial students, hence the name, come from various parts of the world, foreign to the typical Filipino community trending in Philippine School Doha. It is worth considering their demographics and addressing their advantages as well. It could also point out their level of language proficiency, because it varies from country to country, rooting from their families as well. Families have always come in diverse structural forms, reflecting norms of social obligation, biological and emotional ties, cultural values, political movements, and economic conditions (Few-Demo and Demo, 2015). Webb, et. Al. (2019) argues that race is a compound concept, one that is difficult to define. The nature of race over time has kept it as a powerful concept and one that has maintained a unique hegemony allowing it to subordinate some groups to others who do not share the traits of those in power. Based upon the results gathered in a research conducted by Grigera (2017), it appears that multiracial/ethnic individuals with two or more minority statuses have both similar and different experiences as compared to multiracial/ethnic individuals with a dominant condition. Findings highlight numerous internal and external factors as being influential in their racial/ethnic identity development. Findings did in a research conducted by Mahathir, et. Al. (2016) showed that despite being disappointed with their limitations in using their heritage languages, the participants employed specific strategies to solve their communication problems. The family structure of immigrant families is associated with the language attitudes of their children (Lee, 2018).

\section{Enculturation}

Enculturation has often been conceptualized as an unconscious process of cultural internalization (Balanovic, 2016). Remote enculturation falls within the cultural socialization category of ethnic/racial socialization. It is a form of enculturation that involves learning aspects of one's heritage culture via indirect or intermittent exposure, or both (Ferguson, et. Al., 2016). Phylogenetically, enculturation is the result of the evolution of human organisms. It is possible by evolved cerebral and extra-cerebral bodily learning mechanisms that make human organisms apt to acquire culturally inherited cognitive practices (Fabry, 2018). Cultural fusion theory shows how newcomers acculturate into the dominant culture and maintain aspects of their minority culture. At the same time, the host culture also fuses elements of the newcomer's culture into the dominant culture to create a combined intercultural identity (Croucher and Kramer, 2016). Students increasingly cross borders to study in a foreign country and live full experience abroad (Carmona, et. Al., 2016). Acculturation and enculturation contribute to academic adjustment, social adjustment, and educational attachment were varied and included behavioral, values, and identity acculturation dimensions as well as behavioral and values enculturation dimensions (Chan, 2019).

There are some students wherein they had difficulties adapting with the dominant culture observed in Philippine School Doha. Living abroad needs adaptation to a new culture, and the outcomes are influenced by various socio-cultural factors (Bierwiaczonek and Waldzus, 2016). A research conducted by Sheikh and Anderson (2018), suggesting a lack of identification with the host culture was associated with lower levels of these education-relevant outcomes. Herrmann and Varnum (2018) propose that people can be bicultural as a function not only of different ethnic or national identities but also because they may have multiple social class identities. Surprisingly, it was shown that social support from non-local peers significantly weakened the positive effect of the integration strategy on psychological adaptation. Also, further analyses on the impact of acculturation strategies and social support on psychological adaptation showed that social support from local peers and non-local peers and acculturation strategies of integration 
interacted to influence only one specific domain of psychological adjustment (Ting Kin, et. Al., 2017).

As a consequence of this new structure of societies, immigrants will use ways of approaching members of the advancing number of available different cultural groups (Van Oudenhoven and Benet-Martinez, 2015). Although a bi-cultural orientation was predominantly positively related to school adjustment of minority students, some studies also identified assimilative attitudes as advantageous for students' academic achievement as well as for their psychological and behavioral adjustment.

Moreover, our research also showed that young people's acculturative attitudes might have a different impact on their school adjustment relative to acculturative behaviors (Makarova and Birman, 2015). The process of adapting to a noncommon culture unfolds through the stress-adaptation-growth dynamic, a process that is rooted in the natural human tendency to achieve an internal equilibrium in the face of adversarial environmental conditions. Moreover, the adaptation process typically begins with the psychological and physiological experiences of dislocation and duress, commonly known as symptoms of culture shock (Kim, 2017). If a person from one culture moves to different cultures, it requires lots of psychological adjustment to adapt and accept the new culture. Furthermore, it becomes even difficult as they have to adjust to the unique culture and manage academic challenges simultaneously (Boruah, 2016). Cross-cultural adaptation is a challenging process while exploring abroad. The inability to understand cultural variation triggers psychological, physical, or behavioral difficulties and maladjustment or misunderstanding (Rozaimie, 2018). Within academics, the significant challenges students faced when enculturation is taking place in them are the different areas of languages, the differences between the educational systems of their previous schools (including the teaching styles of the respective instructors), and their study skills.

Moreover, adapting psychologically problems had two main types of issues (Hao, 2018):

First, the students had many internal emotions such as loneliness, shying away from parents to share their pain, and did not utilize therapy or other campus resources for support, and;

Second, they found it difficult to face some of the incidents like unfair treatment or discrimination.

In some instances, some students yielded opposite interpretations, hinting positive outcomes; they find it easy to adapt to the Filipino-dominant community in Philippine School Doha, despite their cultural backgrounds. As migrant students cope with relocation challenges, communication with left-behind families and friends can enhance their well-being. In contrast, interactions with co-national and local students can facilitate their acculturation to the host country (Lim and Pham, 2016). A study conducted by Sullivan and Kashnubeck-West (2015) yielded results that international students with broad-based social support and an Integration approach to acculturation experienced lower levels of acculturative stress. The findings gathered from another study conducted by Peng and Wu (2019), suggesting that four main pathways exist (host communication competence, host social communication, intercultural transformation necessary, intercultural change advanced) that are necessary for the development of international students' cross-cultural adaptation, and the interlocking bilateral relationships among these pathways are significant and positive. Greater motivation to acculturate was indeed a significant predictor of global student adjustment and increased intentions of pursuing permanent host country residency (Dentakos, et. Al., 2016). Specific intercultural competences and identity orientations may help students feel more satisfied and interact with different groups as ways to achieve international cultural adaptation (Carmona, et. Al., 2016). A language-based model of changing cultural fit (1) estimates individual attainment; (2) reveals clear patterns of adaptation; (3) shows that rapid cultural adaptation reduces the risk of involuntary; and (4) finds that a decline in cultural fit for individuals who had successfully enculturated portends voluntary departure (Srivastava, et. Al., 2017).

\section{Lifestyle}

According to the World Health Organization definition, lifestyle is ways "of living based on identifiable patterns of behavior which can be determined by the interplay between an individual's characteristics, social interactions, and socioeconomic and environmental living conditions." They represent factors that profoundly determine the quality of an individual's health and life. The socioeconomic level affects the lifestyles of children enrolled in the study. Several factors are linked to the geographical area and may depend on the environmental, cultural, and social aspects of the city of residence (Bagordo, 2017). According to Espinoza (2017), ethnicity is biological and historical characters that signify membership in people who share the same origin, language, history, and culture; even when one grows up in a different culture, ethnicity is maintained. Ethnic identity, then, is a person's sense of belonging to a specific ethnicity that derives from an evaluation of and exploration of oneself in comparison to others. A positive sense of ethnic identity has been shown to be associated with better overall adjustment and functioning.

For the interracial students to interact with the dominant culture trending in the Filipino community in Philippine School Doha, they have to learn as they go on with the community and understand one another to avoid conflicts with each other and develop a culturally diverse community within the school premises. A study conducted by Schachner, et. Al. (2016), revealing that the manifestations of both types of policies (two policies being [a] fostering equality and inclusion; and [b] acknowledging cultural pluralism) promote psychological school adjustment (i.e., better well-being and fewer mental and behavioral problems) at the individual level. Schachner, et. Al. (2016) added that at the classroom level, equality and inclusion promote assimilation. The understanding between online and traditional classroom environments, and how culture manifests itself, can help in shaping a positive educational experience for students (Milheim, 2017). Cross-cultural interconnectedness within an expatriate's social network (not the form of media) contributes to the development of multiculturalism in one's cultural identity (Mao and Shen, 2015). International students with low acculturation motivation (AM) were more likely to express negative feelings about cross-cultural adjustment, university perception, and peer relationships, compared to 
students with high levels of AM. Despite such differences, academic and developmental struggles, as well as academic successes, were similarly voiced across both comparison groups (Dentakos, et. Al., 2016). In the tradition of cross-cultural psychology, acculturation describes individual or ethnocultural group changes in behavior and attitudes in the situation of intercultural contact. Such cultural differences are central to the experience of ethnic minority students, including newly arriving immigrants, children of immigrants, and members of marginalized ethnic and racial groups (Makarova and Birman, 2015).

Contrary to the statements above, some interracial students may find it challenging to adapt to the surrounding school environment. If a person from one culture moves to a different culture, it needs a lot of psychological adjustment to adapt to culture anew. When it comes to students, it becomes difficult as they have to change in the unique culture and manage academic challenges simultaneously (Boruah, 2016).

In most cases between interracial parents, the child has to go through conflicting instances between cultures of both sides of their parents, with the consideration of their choice of where to take their children to study (this is on a contemporary context between academics and culture). This pressures the child into choosing one over the other, frustrating the opposed parent, based on the decision of the child, should the problem arise. Debs (2016) suggests the importance of incorporating parent and student's experience of school choices as complex, interpretive, and ongoing evaluations into broader discussions of structural obstacles and parental resources. Parents influence their children's educational experiences in part via school selection. This process is particularly complicated for families with multiple minorities, potentially stigmatized statuses (Goldberg, et. Al., 2018). It is worth considering that both the parent and the students expressed perspectives on school culture and climate that were consistently different than the perspective expressed by the school personnel (Boham, 2016). In addition to that, differences in racial identity development between students and their parents were identified at the immersion/resistance stage at the internalization stage. Conflict in intercultural marriage regarding childrearing is involved, not only because of the values and beliefs one holds but also because of challenges within the union. Other problems include language, religion, nonverbal cues, and cultural dimensions (Zavala, 2019). Another study was conducted by Hasan (2018), examining the school choices of Muslim parents and the social and academic experiences of Muslim students (this study is under the consideration of religious context under culture). The study demonstrated that most Muslim students in either Islamic or public schools didn't encounter social challenges any different than other students; also, an overload of schoolwork was reported as an academic challenge.

In some instances, some students were able to adapt to the Filipino-dominant PSD community, including an understanding of one another and learning each other's culture through lived experience or otherwise. A phenomenological case study was conducted by Bajamal (2017), exploring the lived experiences of Saudi "third culture kids" (TCKs) and how children, as well as their parents and teachers, describe their experiences as children growing up between different cultures. Findings showed that
Saudi TCKs have positive cultural adaptation during their lived experience, developing their identities as Saudi Muslims and Arabs with developing a bicultural perspective. Therefore, it means that there is a distinct possibility that students can adapt to other cultures based on their lived experiences in the college community with a majority of American and other English-speaking students.

\section{CONCLUSIONS}

Philippine School Doha was once a small school, offering education to only Filipinos. With the school's expansion, the institution now provides quality education to non-Filipino students, or widely known as 'international students.' In line with this, the school is being greeted with multiracial students, unknown to what will strike them firsthand. The culture present in the school is nothing like the other schools' multiracial students came from. Therefore, they would experience culture shock, difficulties in engulfing themselves with the community there. If a person from one culture moves to different cultures, it need a lot of psychological adjustment to adapt to a new culture. When it comes to students, it becomes difficult as they have to adjust to the unique culture and manage academic challenges simultaneously (Boruah, 2016). Cross-cultural adaptation is a process while sojourning abroad. The inability to understand cultural variation triggers psychological, physical, or behavioral difficulties and maladjustment or misunderstanding (Rozaimie, 2018).

Situations vary from time to time, from who they are speaking with, and from what race they originated from. Understanding this concept requires an extensive knowledge, as wide as the school can provide with interracial students because there is a variety of races in which one is proficient than the other in the aspects of communication and the English Language Proficiency (since the English language is spoken universally, though its deliver differs from race to race) (Kim and Tatar, 2017). Situations also vary in difficulty in coping and social engagement, also depending on the speaker him/herself. Findings showed that some students experience difficulties in engaging with the dominant Filipino culture. Others don't know due to closeness of relativity with the Filipino culture (could be of Asian race or a race close to Filipinos). Living abroad needs adaptation to the new culture, and adaptation outcomes are influenced by various socio-cultural factors (Bierwiaczonek and Waldzus, 2016), similar thought applies in the institutional (school) context. Some of the participants were half-Filipino, which rendered him advantageous in all necessary aspects like culture and language of both races of his parents' side. However, he is one of the many halfFilipino multiracial students registered in PSD. Schachner, et. Al. (2016) states that at the classroom level, equality and inclusion promote assimilation.

There were accounts from the findings part of this paper, mentioning cultural choice and conflict between parents. It is understandable for the fact that interracial parents may find a hard time 'accepting' each other's culture and weighing upon which culture is best for their child. Conflict in intercultural marriage regarding childrearing is involved, not only because of the values and beliefs one 
holds but also because of challenges within the union. Other problems include language, religion, nonverbal cues, and cultural dimensions (Zavala, 2019). It is worth considering that both the parent and the students expressed perspectives on school culture and climate that were consistently different than the perspective expressed by the school personnel (Boham, 2016).

The researchers of this paper recommend a further investment of time and observation in this research in order to cover every aspect relating to interracial students for higher variance and to avoid biases, as topics like culture and race are a sensitive topic to conduct a research on, as this could often not be accepted by readers of all races, and conflicts could happen at the end of the road. The researchers also suggest a more in-depth investigation in this matter to generate possible solutions in assisting those in difficulty in coping up with such situations, be it with their family or with the multicultural community.

\section{REFERENCES}

[1] Al Nakhalah, A. M. M. (2016). Problems and difficulties of speaking that encounter English language students at Al Quds Open University. International Journal of Humanities and Social Science Invention, 5(12), 96-101.

[2] Arellano, E. C., Torres, M. F., \& Valentine, K. (2009). Interactional diversity in border colleges: Perceptions of undergraduate students. Journal of Hispanic Higher Education, 8, 282-297.

[3] Bagci, S. C., Rutland, A., Kumashiro, M., Smith, P. K., \& Blumberg, H. (2014). Are minority status children's cross-ethnic friendships beneficial in a multiethnic context? British Journal of Developmental Psychology, 32(1), 107-115.

[4] Bagordo, F., De Donno, A., Grassi, T., Guido, M., Devoti, G., Ceretti, E., . . Carraro, E. (2017). Lifestyles and socio-cultural factors among children aged 6-8 years from five italian towns: The MAPEC_LIFE study cohort. BMC Public Health, 17

[5] Bajamal, H. F. (2017). Saudi third culture kids: A phenomenological case study of saudis' acculturation in a northeast ohio elementary school (Order No. 10610129). Available from ProQuest Dissertations \& Theses Global. (1905848963)

[6] Balanovic, J. (2016). Capturing Enculturation Awareness: Conscious Negotiations between Culture and the Self.

[7] Bierwiaczonek, K., \&Waldzus, S. (2016). Socio-cultural factors as antecedents of cross-cultural adaptation in expatriates, international students, and migrants: A review. Journal of Cross-Cultural Psychology, 47(6), 767-817.

[8] Bogulski, C. A., Bice, K., \& Kroll, J. F. (2019). Bilingualism as a desirable difficulty: Advantages in word learning depend on regulation of the dominant language. Bilingualism: Language and Cognition, 22(5), 1052-1067.

[9] Boham, S. L. (2016). The relationship between intergenerational educational experiences, school culture/climate, and racial identity among americanindian high school students (Order No. 10254815). Available from ProQuest Central; ProQuest Dissertations \& Theses Global; Social Science Premium Collection. (1859675375).

[10] Bonam, C. M., \& Shih, M. (2009). Exploring multiracial individuals' comfort with intimate interracial relationships. Journal of Social Issues, 65, 87-103. doi:10.1111/j.1540- 4560.2008.01589.x

[11] Boruah, A. (2016). A study on socio-cultural adaptation and psychological distress among international students using social support as a moderator. International Journal of Education and Management Studies, 6(2), 180-185.

[12] Carmona, C., Van der Zee, K. I., Van Oudenhoven, J. P., \&Hernaiz-Agreda, N. (2016). Intercultural Competences and Self-Identity as Key Factors to Adaptation.

[13] Chan, S. Y. S. (2019). Balancing the cultural adaptation equation: A concurrent examination of acculturation and enculturation effects on adjustment among asianamericans (Order No. 13424513). Available from ProQuest Dissertations \& Theses Global. (2267898981)

[14] Choi-Misailidis, S. (2010). Multiracial-heritage awareness and personal affiliation (M-HAPA): Understanding identity in people of mixed-race descent. In J. Ponterotto, J. Casas, L. Suzuki, \& C.
Alexander (Eds.), Handbook of multicultural counseling (pp. 301-311) Thousand Oaks, CA: Sage

[15] Croucher, S. M., \& Kramer, E. (2016). Cultural fusion theory: An alternative to acculturation. Journal of International and Intercultural Communication, 10(2), 97-114.

[16] Deaux, K. (2001). Social identity. In J. Worrell (Ed.), Encyclopaedia of women and gender (pp. 1059-1067). San Diego, CA: Academic Press.

[17] DeBose, H. L., \& Winters, L. I. (2003). The dilemma of biracial people of African American descent. In L. I. Winters \& H. L. DeBose (Eds.), New faces in a changing America: Multiracial identity in the $21 \mathrm{st}$ century (pp. 127-157). Thousand Oaks, CA: Sage

[18] Debs, M. (2016). Diverse parents, desirable schools: Public montessori, fit and conflict in the era of school choice (Order No. 10583227). Available from ProQuest Central; ProQuest Dissertations \& Theses Global; Social Science Premium Collection. (1923434783).

[19] Dentakos, S., Wintre, M., Chavoshi, S. (2016). Acculturation motivation in international student adjustment and permanent residency intentions: a mixed-methods approach.

[20] Dentakos, S., Wintre, M., Chavoshi, S., \& Wright, L. (2017). Acculturation Motivation in International Student Adjustment and Permanent Residency Intentions: A Mixed-Methods Approach Emerging Adulthood, 5(1), 27-41.

[21] Epstein and Heizler (2015). Ethnic Identity: A Theoretical Framework. 4:9 DOI 10.1186/s40176-015-0033-z

[22] Espinoza, J. (2017). A psychoeducational group between two cultures: Navigating ethnic identity for parents of internationally-adopted children (Order No. 10635291). Available from ProQuest Dissertations \& Theses Global. (1972887653).

[23] Fabry, R. E. (2018). Enculturation and narrative practices. Phenomenology and the Cognitive Sciences, 17(5), 911-937.

[24] Ferguson, G. M., Costigan, C. L., Clarke, C. V., \& Ge, J. S. (2016). Introducing remote enculturation: Learning your heritage culture from afar. Child Development Perspectives, 10(3), 166-171.

[25] Few-Demo, A. L., \& Demo, D. H. (2015). Family Diversity. The Wiley Blackwell Encyclopedia of Race, Ethnicity, and Nationalism, 1-8.

[26] Fisher, S., Reynolds, J. L., Hsu, W., Barnes, J., \& Tyler, K. (2014). Examining multiracial youth in context: Ethnic identity development and mental health outcomes. Journal of Youth and Adolescence, 43(10), 1688-99.

[27] Franco, M. G., Katz, R., \& O’Brien, K. M. (2016). Forbidden identities: A qualitative examination of racial identity invalidation for Black/White Biracial individuals. International Journal of Intercultural Relations, 50, 96-109. doi:10.1016/j.ijintrel.2015.12.004

[28] Gaither, S. E. (2015). "Mixed" results multiracial research and identity explorations. Current Directions in Psychological Science, 24, 114-119. doi:10.1177/0963721414558115

[29] Gaither, S. E., Sommers, S. R., \&Ambady, N. (2013). When the half affects the whole: Priming identity for biracial individuals in social interactions. Journal of Experimental Social Psychology, 49, 368-371. doi:10.1016/j.jesp.2012.12.012

[30] God, Y. T., \& Zhang, H. (2019). Intercultural challenges, intracultural practices: How Chinese and Australian students understand and experience intercultural communication at an Australian university. Higher Education, 78(2), 305-322.

[31] Goldberg, A. E., Allen, K. R., Black, K. A., Frost, R. L., \& Manley, M. H. (2018). "There is no perfect school": The complexity of school decision-making among lesbian and gay adoptive parents. Journal of Marriage and Family, 80(3), 684-703.

[32] Gonzales-Backen, M. (2013). An application of ecological theory to ethnic identity formation among biethnic adolescents. Family Relations, 62(1), 92-108

[33] Gonzalez, E. (2016). Ethnic-racial attitudes and indigenous identity among Oaxaqueño/a adolescents and young adults (Order No. 10140266). Available from ProQuest Central; ProQuest Dissertations \& Theses Global. (1805865908).

[34] Goodyer, A., \&Okitikpi, T. (2007). “. . . But . . . But I am Brown.” The ascribed categories of identity: Children and Young people of mixed parentage. Child Care In Practice. 13, 83- 94.

[35] Graham, S., Munniksma, A., \& Juvonen, J. (2014). Psychosocial benefits of cross-ethnic friendships in urban middle schools. Child Development, 85(2), 469-483.

[36] Green, J. A. (2015). The effect of English proficiency and ethnicity on academic performance and progress. Advances in Health Sciences Education, 20(1), 219-228.

[37] Grigera, R. (2017). A Qualitative Study of the Experiences of Multiracial/Ethnic Minority Individuals (Doctoral dissertation, The Chicago School of Professional Psychology).

[38] Gulf News (2018, May 07). How multiculturalism helps schoo education

from 
https://search-proquest.com.eres.qnl.qa/docview/2035271290?account id $=49936$

[39] Han, A. L. (1996). How asian-american women deal with bicultural values and expectations in relation to their parents: Their use of influence strategies and coping strategies (Order No. 9705857). Available from ProQuest Dissertations \& Theses Global. (304283442).

[40] Han, E. (2012). A qualitative study examining influences in identity development for biracial adolescents and emerging adults.(Doctoral Dissertation.) Michigan State University, Michigan, United States

[41] Hao, J. (2018). Being an international student: Experiences of chinese undergraduate students in a large research university (Order No. 10936720). Available from ProQuest Dissertations \& Theses Global. (2133643717)

[42] Hao, J. (2018). Being an international student: Experiences of chinese undergraduate students in a large research university (Order No. 10936720). Available from ProQuest Dissertations \& Theses Global. (2133643717).

[43] Harris, H. L., PhD. (2013). A NATIONAL SURVEY OF SCHOOL COUNSELORS' PERCEPTIONS OF MULTIRACIAL STUDENTS Professional School Counseling, 17(1), 1-19.

[44] Hasan, R. (2018). Islamic schools vs. public schools: A case study of the school choices of muslim parents and the social and academic experiences of students and young adults (Order No. 10689851). Available from ProQuest Central; ProQuest Dissertations \& Theses Global. (1986011871).

[45] Haugh, M. (2016). Complaints and troubles talk about the English language skills of international students in Australian universities. Higher Education Research \& Development, 35(4), 727-740.

[46] Herrmann, S. D., \&Varnum, M. E. W. (2018). Utilizing social class bicultural identity integration to improve outcomes for first-generation college students. Translational Issues in Psychological Science, 4(2), $165-175$.

[47] Hitti, A., Mulvey, K.L., Killen, M. (2017) Handbook on Positive Development of Minority Children and Youth. DOI 10.1007/978-3-319-43645-6_17

[48] Hogg, M. A. (2016). Social identity theory. In S. McKeown, R. Haji, \& N. Ferguson (Eds.), Understanding peace and conflict through social identity theory (pp. 3-19). Cham, Switzerland: Springer Publishing.

[49] Hsieh, M. (2016). Ecological perspective: Identity formation within interracial and multicultural families (Order No. 10103388). Available from ProQuest Central; ProQuest Dissertations \& Theses Global. (1789111678).

[50] Kim, J., \& Tatar, B. (2017). Nonnative English-speaking professors' experiences of English-medium instruction and their perceived roles of the local language. Journal of Language, Identity \& Education, 16(3), 157-171.

[51] Kim, Y. Y. (2017). Cross-cultural adaptation. In Oxford Research Encyclopedia of Communication.

[52] Kroll, J. F., \&Dussias, P. E. (2017). The benefits of multilingualism to the personal and professional development of residents of the US Foreign language annals, 50(2), 248-259.

[53] Lee, H. Y. H. (2018). The Effect of Multicultural Family Structures on the Language Attitudes of Children and Adolescents. GEMA Online® Journal of Language Studies, 18(1).

[54] Mahathir, M., Nor, N. F. M., \&Azman, H. (2016). Vignettes: An Alternative Qualitative Method for Studying Mixed-Heritage Individuals with Limited Heritage Language Abilities. In Qualitative Research Conference Proceedings (QRC) (pp. 24-26).

[55] Makarova, E. and Birman, D. (2014). Cultural transition and academic achievement of students of empirical research on acculutration.

[56] Makarova, E., \& Birman, D. (2015). Cultural transition and academic achievement of students from ethnic minority backgrounds: A content analysis of empirical research on acculturation. Educational Research, 57(3), 305-330.

[57] Mao, J., \& Shen, Y. (2015). Cultural identity change in expatriates: A social network perspective. Human Relations, 68(10), 153-31556.

[58] Mart, Ç. T. (2017). Literary texts: A means to promote language proficiency of upper-intermediate level EFL students. Journal of Education in Black Sea Region, 2(2), 44-55.

[59] Martirosyan, N. M., Hwang, E., \&Wanjohi, R. (2015). Impact of English proficiency on academic performance of international students. Journal of International Students, 5(1), 60-71.

[60] Milheim, K. (2017). A Fundamental Look at Cultural Diversity and the Online Classroom. eLearn, 2017(2), 1.

[61] Mohamad, M. (2019). Ethnicity, Political Parties and Election in Malaysian Politic; Political Parties in Malaysia based on Ethnicity?

[62] Ng, T. K., Wang, K. W. C., \& Chan, W. (2017). Acculturation and cross-cultural adaptation: The moderating role of social support. International Journal of Intercultural Relations, 59, 19-30.
[63] Padilla-Díaz, M. (2015). Phenomenology in educational qualitative research: Philosophy as science or philosophical science. International Journal of Educational Excellence, 1(2), 101-110.

[64] Park, E., Klieve, H., Tsurutani, C., \& Harte, W. (2017). International students' accented English-Communication difficulties and developed strategies. Cogent Education, 4(1), 1314651

[65] Peng, R. Z., \& Wu, W. P. (2019). Measuring communication patterns and intercultural transformation of international students in cross-cultural adaptation. International Journal of Intercultural Relations, 70, 78-88.

[66] Phinney, J. S. (2006). Ethnic identity exploration in emerging adulthood. In D. L. Browning (Ed). Adolescent identities (pp. 47-63). London: The Analytic Press.

[67] Prevoo, M. J., Malda, M., Mesman, J., \& van IJzendoorn, M. H. (2016). Within-and cross-language relations between oral language proficiency and school outcomes in bilingual children with an immigrant background: A meta-analytical study. Review of Educational Research 86(1), 237-276.

[68] Raines, C. J. (2015). Racial socialization, racial identity, and acculturative stress among africanamerican adolescents from three racially distinct neighborhoods (Order No. 3715430). Available from ProQuest Dissertations \& Theses Global. (1711148446).

[69] Renn, K. A. (2008). Research on biracial and multiracial identity development: Overview and synthesis. In K. A. Renn\& P. Shang (Eds.), Biracial and multiracial students: New directions for student services (No. 123, pp. 13-21). San Francisco, CA: Jossey-Bass.

[70] Rios, K. S. (2018). The effects of interracial couples raising biracial children (Order No. 10285111). Available from ProQuest Dissertations $\&$ Theses Global. (1914677135).

[71] Rosselli, M., Ardila, A., Lalwani, L. N., \&Vélez-Uribe, I. (2016). The effect of language proficiency on executive functions in balanced and unbalanced Spanish-English bilinguals. Bilingualism: Language and Cognition, 19(3), 489-503.

[72] Rozaimie, A. (2018). Cultural variations and socio-ecocultural understanding of cross-cultural adaptation. The Qualitative Report, 23(10), 2538-2551

[73] Rozaimie, A. (2018). Cultural variations and socio-ecocultural understanding of cross-cultural adaptation. The Qualitative Report 23(10), 2538-2551.

[74] San Miguel, C., \& Rogan, F. (2015). Assessing students' English language proficiency during clinical placement: A qualitative evaluation of a language framework. Nurse education today, 35(6), $771-776$

[75] Sanchez-Paramo, N. (2014). Perspectives of multiracial educators of multiracial children: Understanding how they navigate their identity in school and society (Order No. 3620304). Available from ProQuest Central; ProQuest Dissertations \& Theses Global; Social Science Premium Collection. (1538041129).

[76] Schachner, M. K., Noack, P., Van de Vijver, F.,J.R., \& Eckstein, K (2016). Cultural diversity climate and psychological adjustment at school-equality and inclusion versus cultural pluralism. Child Development, 87(4), 1175-1191.

[77] Shak, P., Lee, C. S., \& Stephen, J. (2016). Pronunciation problems: A case study on English pronunciation errors of low proficient students International Journal of Language Education and Applied Linguistics.

[78] Sheikh, M., \& Anderson, J. R. (2018). Acculturation patterns and education of refugees and asylum seekers: A systematic literature review. Learning and Individual Differences, 67, 22-32.

[79] Solis, P. (2019). Ethnic/Racial Discrimination in Mexico: A Taxonomy of Discrimination Practices. El Colegio de México.

[80] Srivastava, S. B., Goldberg, A., Manian, V. G., \& Potts, C. (2017). Enculturation trajectories: Language, cultural adaptation, and individual outcomes in organizations. Management Science, 64(3), 1348-1364.

[81] Sullivan, C., \&Kashubeck-West, S. (2015). The interplay of international students' acculturative stress, social support, and acculturation modes. Journal of International Students, 5(1), 1-11.

[82] Teasley, D. (n.d.). Interracial Marriage: Definition, History, \& Laws Retrieved

fromIhttps://study.com/academy/lesson/interracial-marriage-definition -history-laws.html

[83] Van Oudenhoven, J. P., \& Benet-Martínez, V. (2015). In search of a cultural home: From acculturation to frame-switching and intercultural, competencies. International Journal of Intercultural Relations, 46, 47-54.

[84] Verreyt, N., Woumans, E. V. Y., Vandelanotte, D., Szmalec, A., \&Duyck, W. (2016). The influence of language-switching experience on the bilingual executive control advantage. Bilingualism: Language and Cognition, 19(1), 181-190. 
[85] Watson, J. (2019). Why is Teen Identity Development Important? Retrieved from aspiroadventure.com/blog/why-is-teen-identity-development-importan t/

[86] Webb, F. J., Burrell, J., \& Jefferson, S. G. (2019). Social constitutionality of race in America: Some meanings for bi/multiracial families. In Biracial Families (pp. 9-32). Springer, Cham.

[87] Whiteside, K. E., Gooch, D., \&Norbury, C. F. (2017). English language proficiency and early school attainment among children learning English as an additional language. Child development, 88(3), 812-827.

[88] Worrell, F. C. (2015). Culture as race/ethnicity. In K. T. McLean \& M Syed (Eds.), The Oxford handbook of identity development (pp. 249-268). New York: Oxford University Press.

[89] Zavala, D. (2019). Challenges and conflicts in intercultural marriages: Creating solutions in childrearing (Order No. 13882420). Available from ProQuest Dissertations \& Theses Global. (2297417030). 